\title{
Thrombospondin Inhibits VEGF-Induced Endothelial Survival and Cell Cycle Progression
}

\author{
Kalpna Gupta*, ${ }^{*}$, Robert Schwartz ${ }^{1}$, Pankaj Gupta ${ }^{2}$ and Robert P Hebbel ${ }^{1}$ \\ ${ }^{I}$ Vascular Biology Center, Division of Hematology, Oncology and Transplantation, University of Minnesota and the \\ ${ }^{2}$ Hematology-Oncology Section, Veterans Affairs Medical Center,Minneapolis, Minnesota
}

\begin{abstract}
Thrombospondin (TSP) is an anti-angiogenic protein that inhibits vascular endothelial growth factor (VEGF)induced endothelial cell growth and survival. We examined the intracellular mechanism(s) of the inhibition of VEGFinduced endothelial survival by TSP. We show that antibodies against the type I-, type II-, type-III repeats, carboxy terminal domain and N-terminal region of TSP blocked TSP-induced endothelial apoptosis. TSP promotes apoptosis by stimulating the release of cytochrome $\mathrm{c}$ from mitochondria and activating caspase-3 activity and cleavage of poly-ADPribose-polymerase (PARP). In addition, TSP inhibits VEGF-induced cell cycle progression in the G0/G1, S and G2/M phases of the cell cycle. The inhibitory effect of TSP on the cell cycle is accompanied by inhibition of cyclins A- and Edependent kinase activity and prevention of the translocation of cell cycle regulatory proteins cyclins A and $\mathrm{E}$ to the nucleus. Furthermore, TSP upregulates the cell cycle regulatory phosphatases $\mathrm{p} 21^{\mathrm{CIP} / \mathrm{WAF}-1}$ and $\mathrm{p} 27^{\mathrm{KIP}-1}$. These results suggest that TSP stimulates apoptosis and cell cycle arrest by stimulating cytochrome $\mathrm{c}$ release and activation of caspase-3 activity; and inhibition of cell cycle regulatory checkpoints involving cyclin A and E dependent kinases that are in turn controlled by upregulation of $\mathrm{p} 21^{\mathrm{CIP} / \mathrm{WAF}-1}$ and $\mathrm{p} 27^{\mathrm{KIP}-1}$. Our data suggest the possibility that different domains of TSP are associated with the anti-angiogenic activity of TSP utilizing both endothelial apoptosis and cell cycle arrest.
\end{abstract}

Keywords: Thrombospondin, vascular endothelial growth factor, apoptosis, cell cycle, angiogenesis, cytochrome c.

\section{INTRODUCTION}

Angiogenesis as well as the quiescence of vasculature are determined by interplay between the positive and negative stimuli in the endothelial vicinity [1]. Amongst several identified regulators of angiogenesis, vascular endothelial growth factor (VEGF) is a specific growth stimulating factor and thrombospondin (TSP) an inhibitory factor [1-4]. TSP and other endothelial growth inhibitory proteins such as angiostatin and endostatin are endogenous proteins that may be useful for developing anti-angiogenic therapy for limiting pathological neovascularization [5-8]. One common feature shared by these molecules is that they block the growth promoting effect of the growth factors and promote apoptosis [9-11]. We showed earlier that TSP prevents VEGF-induced endothelial cell (EC) proliferation and angiogenesis by displacing VEGF and also by directly binding to VEGF [12].

On the other hand, TSP stimulates pro-apoptotic signaling by abrogating $\mathrm{Bcl} 2$, by activating caspases, and by cell surface CD36-mediated stimulation of intracellular signals Fyn, p38 MAPK and TNF receptor1 [9, 11, 13]. However, TSP-1 mediated angiogenic activity could not be completely abrogated using anti-CD36 antibodies or CD-36 binding peptides $[14,15]$. While CD36 mediated signaling plays a critical role in anti-angiogenic activity, TSP may also

\footnotetext{
*Address correspondence to this author at the Division of Hematology, Oncology and Transplantation, University of Minnesota, Mayo Mail Code 480, 420 Delaware Street SE, Minneapolis, Minnesota 55455, USA;

Tel: 612-625-7648; Fax: 612-625-6919; E-mail: gupta014@umn.edu
}

be acting in a CD36-independent manner. Since TSP is comprised of multiple heterogeneous domains that interact with several endothelial cell surface receptors, it is likely that it activates several intracellular signaling pathways.

Moreover, in most cellular systems apoptosis and cell growth are tightly connected [16-18]. The convergence of the two is required for the growth and development of the vasculature. These pathways may converge to a common downstream signaling cascade leading to cell cycle arrest and inhibition of endothelial growth and survival. Dysregulated progression of the cell cycle is a characteristic feature of tumor growth [19]. Drugs disrupting the cell cycle regulatory process can therefore be more effective chemotherapeutic and/or anti-angiogenic agents. Recent studies suggest an increased expression of TSP-1 following chemotherapy and anti-angiogenic therapy [20, 21]. It is possible that TSP-1 inhibits angiogenesis by blocking cell cycle progression and potentiates the therapeutic effect of chemotherapeutic and/or anti-angiogenic agents.

Cell cycle regulation by cyclin-dependent kinase inhibitors (CDK-I) such as p21 $1^{\mathrm{CIP} / \mathrm{WAF}-1}$ and $\mathrm{p} 27^{\mathrm{KIP}-1}$ (called p21 and p27) is critical in maintaining cell cycle arrest in serum-starved or quiescent cells [22,23]. An increase in these CDK-Is inhibits cell cycle progression leading to the inhibition of cell proliferation. Cycling endothelial cells are considered to be more sensitive to low dose metronomic therapies as compared to continued low dose therapy [20, 24]. Recent observations further suggest that metronomic dosing of chemotherapeutic drugs upregulates TSP-1 expression and promotes the anti-angiogenic effect [20]. TSP does not affect the growth or apoptosis of normal or 
quiescent endothelium. It only influences neovascularization driven by growth-promoting cytokines and growth factors in the endothelial microenvironment. We therefore hypothesized that TSP can affect cell cycle regulatory proteins leading to cell cycle arrest as well as apoptosis.

VEGF is an endothelial cell specific growth factor and has been strongly implicated in the promotion of angiogenesis-dependent tumor growth [25-28]. We envisage that TSP inhibits VEGF-induced survival signaling and cell cycle progression. An insight into the mechanism(s) of inhibition of VEGF activity by TSP in endothelium can have important implications in extending the use of TSP as a potent anti-angiogenic agent. To examine this possibility, all our studies were performed on VEGF stimulated EC. Controls without VEGF were also used to see the basal effect of TSP on unstimulated, quiescent endothelium. We show here that TSP stimulates apoptosis by activating mitochondrial cytochrome c release and inhibits cell cycle progression by modulating cell cycle check-points and regulatory proteins, p27 and p21. We also show that different domains of TSP participate in its pro-apoptotic activity.

\section{MATERIALS AND METHODS}

\section{Reagents}

Antibodies were obtained as follows: EN4 (antiendothelial cell) from Monosan, The Netherlands; antibodies A4.1, A6.1, D4.6, C6.7 and 9 against the type I, type II, type III, carboxy terminal domain and N-terminal region of TSP, respectively (Neo-markers, Fremont, CA); anti-TGF $\beta$ from R\&D Systems, Minneapolis, MN; anti-PARP and caspase-3 from Pharmingen, San Diego, CA; anti-actin and cell cycle protein antibodies, p21, p27, cyclin A and cyclin E from Santa Cruz Biotechnology, Santa Cruz, CA; anti-cytochrome c from Molecular Probes, Eugene, OR; and species specific secondary antibodies conjugated with FITC or PE from Jackson ImmunoResearch Laboratories, Inc., West Grove, PA. Caspase inhibitor Z-VAD-FMK (carbobenzoxy-valylalanyl-aspartyl-[O-methyl]-fluoromethylketone) was obtained from Promega, San Luis Obispo, CA. Other chemicals were from Sigma, St Louis, MO and cell culture reagents from Life Technologies Inc., Gaithersburg, MD unless specified.

\section{Preparation of TSP}

TSP was purified from fresh human platelets (obtained from American Red Cross, Minneapolis, MN) using a sodium chloride gradient on a heparin-agarose column followed by size fractionation on a Biorad A $0.5 \mathrm{~m}$ gel column, as described by us earlier [12]. Homogeneity of the protein was confirmed by SDS-PAGE and silver staining. Additionally the purity of TSP was also confirmed by Western immunoblotting using anti-PF4 and anti-TGF- $\beta$ antibodies. We found our preparation to be homogenous showing only three bands in the $150 \mathrm{kD}$ range, typical of TSP. We did not observe any signal for either PF4 or TGF-B on immunoblotting.

\section{Cell Culture}

We isolated human dermal microvascular endothelial cells (HDMEC) from neonatal human foreskins and confirmed their homogeneity as described [29]. Culture medium consisted of medium MCDB 131 (GIBCO BRL, Gaithersburg, MD), with $1 \mu \mathrm{g} / \mathrm{ml}$ hydrocortisone acetate, $5 \mathrm{x}$ $10^{-4} \mathrm{M}$ dibutyryl cAMP, $10 \mathrm{mM}$ L-glutamine, $100 \mathrm{U} / \mathrm{ml}$ penicillin, $100 \mathrm{U} / \mathrm{ml}$ streptomycin, $0.25 \mathrm{mg} / \mathrm{ml}$ amphotericin $\mathrm{B}, 0.004 \%$ heparin, $10 \mu \mathrm{g} / \mathrm{L}$ epidermal growth factor, and $20 \%$ heat-inactivated male human serum.

\section{Cell Fractionation and Mitochondrial Isolation}

After respective stimulations with and/or without VEGF/TSP, mitochondrial and cytoplasmic fractions of HDMEC were separated as described [30]. Purity of the mitochondrial and cytosolic fractions was confirmed by Western immunoblotting using anti-cytochrome c (Pharmingen) and anti-sarcomeric $\alpha$-actin (Sigma). We observed that mitochondrial fraction was devoid of sarcomeric actin and that cytosolic fraction was devoid of cytochrome $\mathrm{c}$ in HDMEC grown in complete culture medium (results not shown).

\section{Apoptosis and Cell Cycle Analysis}

We quantitated apoptosis using the TUNEL (terminal deoxynucleotidyl transferase (TdT)-mediated dUTP nick end labeling) assay to detect DNA strand breaks (Cell Death Detection ELISA ${ }^{\text {PLUS }}$, Roche Diagnostics Corporation, Indianapolis, IN) as described [31]. We performed flow cytometric analysis of propidium iodide-labeled cells to quantitate the percentage of cells in $\mathrm{A} 0, \mathrm{G} 0 / \mathrm{G} 1, \mathrm{~S}$ and G2/M phases of the cell cycle, as described [32]. We used a FACSCaliber instrument (Becton Dickinson, Mountain View, CA) and FlowJo software (Becton Dickinson) to calculate the percentage of cells in different phases of the cell cycle.

\section{Cell Cycle Proteins}

Cell cycle protein expression was analysed by Western immunoblotting, cyclin-dependent kinase activity by kinase assays and co-localization in cellular compartments by immunofluorescent staining. For each assay cells were treated in a similar fashion by serum and growth factor starvation for 24 hours, followed by stimulation with VEGF or/and TSP for an additional 48 hours, and assays were performed as described below.

\section{Western Blot Analysis}

Cell lysates (30 $\mu \mathrm{g}$ protein) resolved on a $3-15 \%$ gradient SDS-PAGE gel were transferred to a polyvinylidene difluoride membrane (ImmobilonP; Millipore, Bedford, MA). For immunoblotting we used the primary antibodies described above and as indicated in the results. The immunoreactive proteins were visualized with ECF Western blotting system (Amersham Life Sciences, Buckinghamshire, UK) and chemiluminescent signals were acquired using a Storm 860 Phosphorimager (Molecular Dynamics, Sunnyvale, CA).

\section{Cyclin A and E Associated Kinase Assay}

Cyclins $\mathrm{A}$ and $\mathrm{E}$ were precipitated from cell lysates (containing $1 \mathrm{mg}$ protein) using either $5 \mu \mathrm{g}$ each of Abs $\mathrm{H}$ 432 or M-20 (Santa Cruz), respectively. Kinase activity was assayed by transfer of ${ }^{32} \mathrm{P}$ to Histone $\mathrm{H} 1$ as substrate at $30^{\circ} \mathrm{C}$ for $45 \mathrm{~min}$. Complexes were released from the beads by 


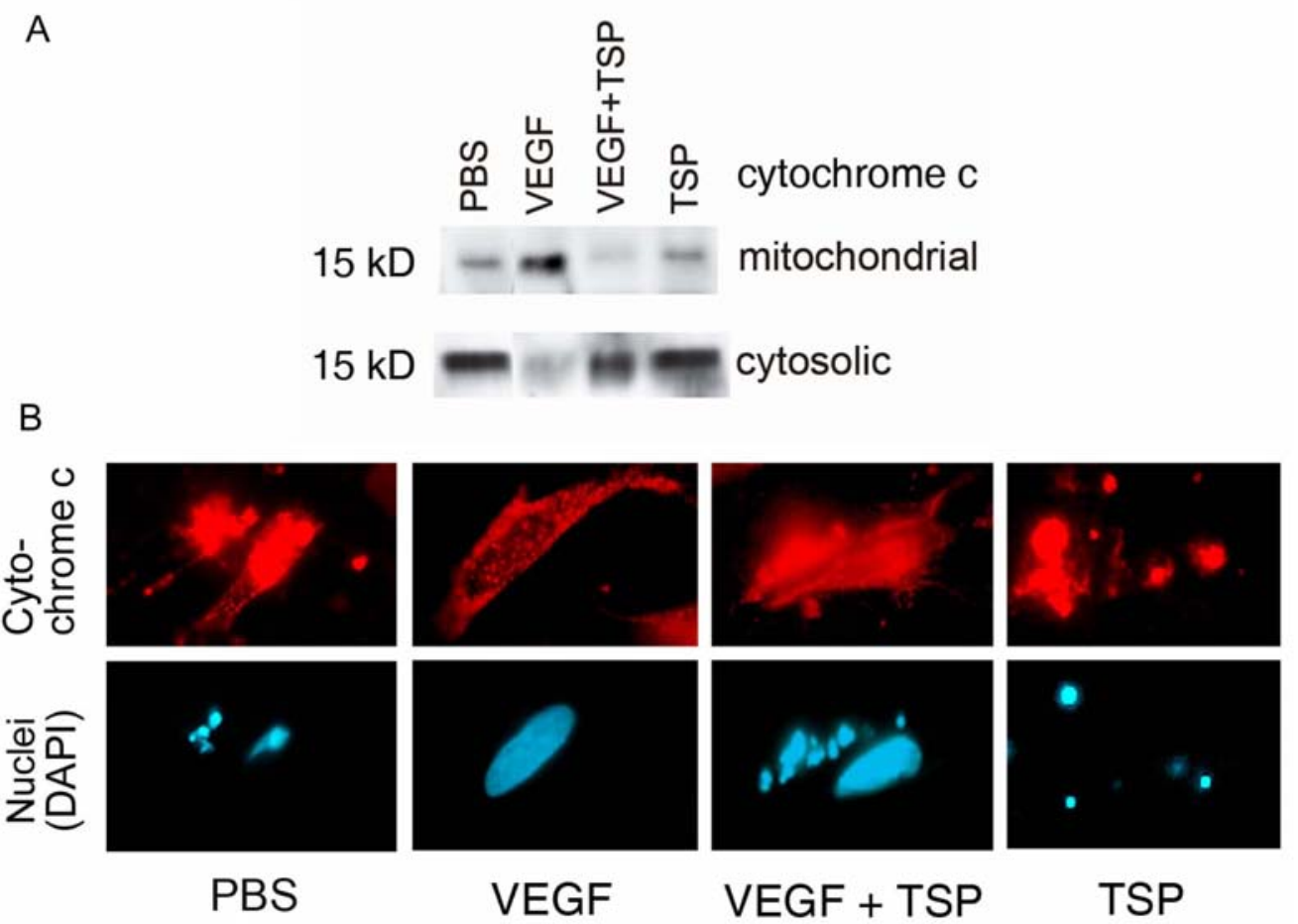

Fig. (1). TSP stimulates release of mitochondrial cytochrome c in VEGF-stimulated endothelial cells: Serum and growth factor-starved HDMEC were incubated with $100 \mathrm{ng} / \mathrm{ml}$ VEGF in the presence or absence of $10 \mathrm{ng} / \mathrm{ml}$ TSP for $48 \mathrm{~h}$ and assayed for cytochrome c using: (A) Western immunoblotting of the lysates from cytosolic and mitochondrial fractions. (B) immunofluorescent microscopy for the colocalization of cytochrome c (red) in the cytoplasmic and the nuclear (blue) region. Magnification X600. Each figure represents 4 separate and reproducible experiments.

heating at $70^{\circ} \mathrm{C}$ for $10 \mathrm{~min}$., followed by separation of proteins on a $3-15 \%$ SDS-PAGE gel. Protein bands were visualized by exposing the gels to X-ray film (Kodak, Rochester, NY).

\section{Immunofluorescent (IF) Co-Localization of Proteins in Cellular Compartments}

Cells on glass slides were fixed with $2 \%$ paraformaldehyde for $10 \mathrm{~min}$ at room temp. and permeabilized with $0.1 \%$ Triton $\mathrm{X}-100$ for $2 \mathrm{~min}$ on ice (where required). Cells were incubated with primary antibodies as shown in the respective figures and with species specific secondary antibodies conjugated with FITC or PE, followed by staining with DAPI for nuclear colocalization. Fluorescent images were acquired using an Olympus 1X70 Inverted Reflected Light Fluorescence Microscope (Olympus America Inc, Lake Success, NY) and Spot digital camera.

\section{Statistical Analysis}

Analysis of variance (ANOVA) was conducted on area under the curve for apoptosis assays and caspase activity. Pairwise contrasts were constructed and tested using t-tests. $\mathrm{P}$-values were adjusted using the method of Bonferroni. For cell cycle analysis, repeated measures ANOVA was conducted to determine whether the percentage of cells in a cycle was affected by phase, treatment, or their combination. Subsequent pairwise contrasts were constructed between treatments and tested using the t-statistic. Results of these pairwise comparisons are presented below.

\section{RESULTS}

\section{TSP Stimulates Apoptosis by Activating Mitochondrial Cytochrome c Release in HDMEC}

Given that TSP has several heterogeneous domains that participate in its anti-angiogenic activity, it could be activating more than one upstream event which can activate the apoptosis/caspase cascade. Therefore, we examined if TSP stimulated the release of cytochrome $c$ from the mitochondria in HDMEC. Western blot analysis of VEGFtreated endothelial cells showed the presence of cytochrome $\mathrm{c}$ in the mitochondrial fraction but not in the cytoplasmic fraction (Fig. 1A). In contrast, cytochrome $\mathrm{c}$ was detected in the cytoplasmic fraction and not in the mitochondrial fraction of VEGF-treated cells in the presence of TSP (Fig. 1A). In serum and growth factor-starved control cells TSP did not increase cytochrome c release by itself. Therefore, TSP neutralizes the inhibition of VEGF-induced cytochrome $\mathrm{c}$ release from mitochondria. To further confirm the leakage of cytochrome $\mathrm{c}$ from the mitochondria into the cytoplasm, we performed IF staining of cell monolayers. IF staining of monolayers with anti-cytochrome $c$ PE confirmed the localization of cytochrome $\mathrm{c}$ as dense aggregates of red dots suggesting mitochondrial localization in VEGF-treated cells. Cells treated with VEGF in the presence of TSP showed diffused staining all over the cell, indicative of leakage of cytochrome $\mathrm{c}$ from the mitochondria (Fig. 1B). In addition, untreated and TSP-treated cells appeared more rounded and fragmented suggesting an apoptotic phenotype. Nuclear fragmentation under serum-free conditions is suggestive of 


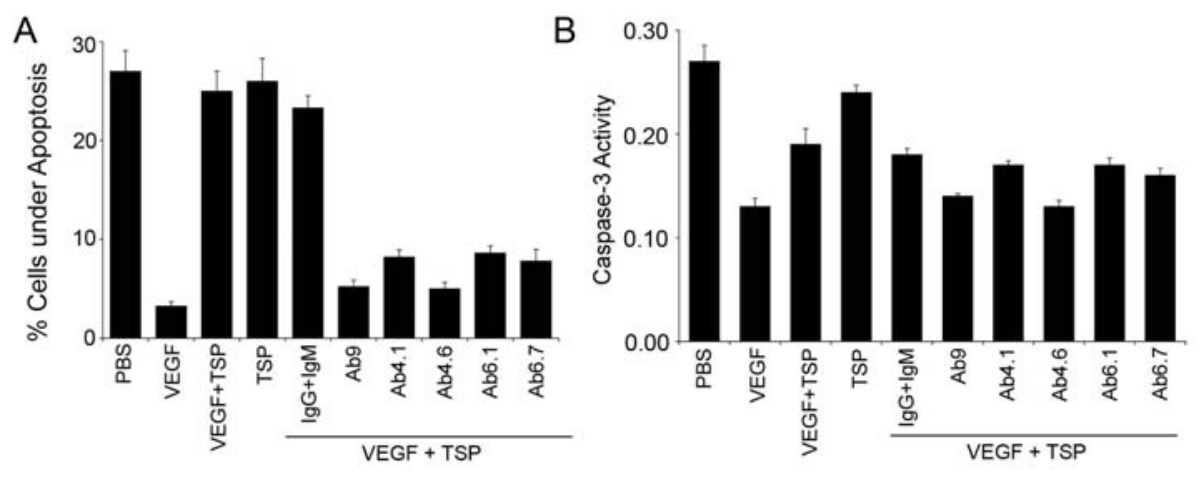

C
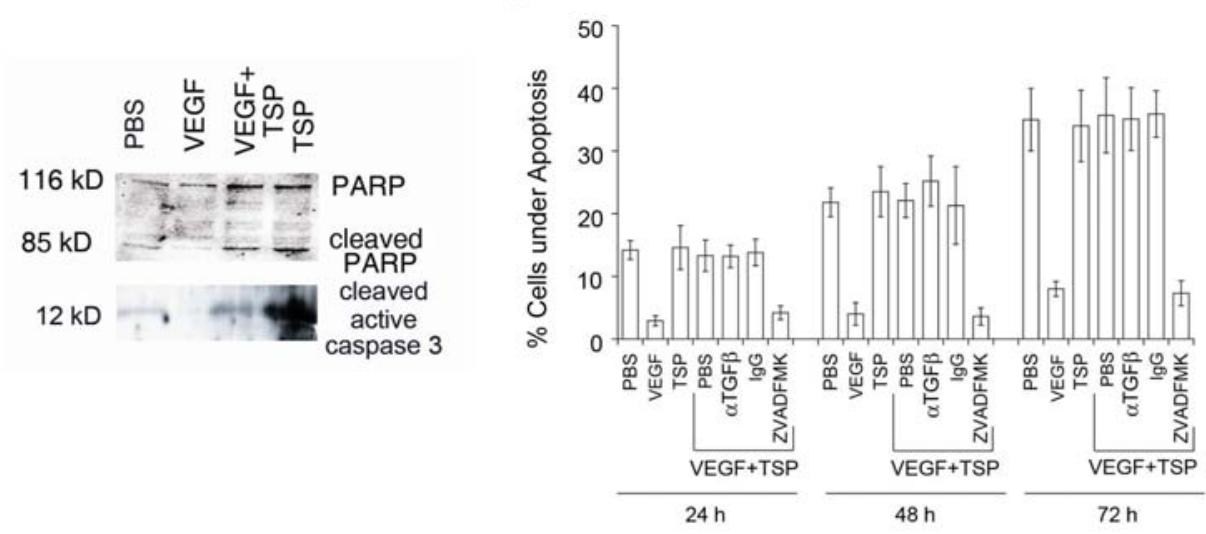

Fig. (2). TSP induces apoptosis in VEGF-stimulated endothelial cells via caspase-3: Serum and growth factor-starved HDMEC were incubated for $48 \mathrm{~h}$ with $100 \mathrm{ng} / \mathrm{ml}$ VEGF in the presence or absence of $10 \mathrm{ng} / \mathrm{ml} \mathrm{TSP}$ with: $5 \mu \mathrm{g} / \mathrm{ml}$ antibodies against different regions of TSP (antibodies A4.1, A6.1, D4.6, C6.7 and 9 against the type I, type II, type III, carboxy terminal domain and N-terminal region of TSP, respectively), incubated for $48 \mathrm{~h}$ and assayed for (A) apoptosis ( $\mathrm{p}<0.0001$ VEGF vs. VEGF+TSP, VEGF+TSP vs. Ab9 or Ab4.1, or Ab4.6 or Ab6.1 or Ab6.7 + VEGF+TSP); (B) caspase-3 activity using ELISA ( $<<0.06$ for VEGF+TSP vs. VEGF+TSP+Ab9 and p<0.05 for VEGF+TSP vs. VEGF+TSP+Ab4.6); (C) Cleavage of PARP and caspase-3 by Western immunoblotting. Each figure represents 4 separate and reproducible experiments. (D) Serum and growth factor-starved HDMEC were incubated for $24 \mathrm{~h}, 48 \mathrm{~h}$ and $72 \mathrm{~h}$ with $100 \mathrm{ng} / \mathrm{ml} \mathrm{VEGF}$ in the presence or absence of $10 \mathrm{ng} / \mathrm{ml}$ TSP with/without anti-TGF $\beta$ or $20 \mu \mathrm{M}$ ZVADFMK (a caspase inhibitor), and analysed for apoptosis ( $\mathrm{p}<0.0001$ VEGF vs VEGF+TSP for 24h, 48h, and 72h and $\mathrm{p}<0.0001$ VEGF+TSP vs. VEGF+TSP+TSP+ZVADFMK 24h, 48h and 72h). Each value in $A, B$ and $D$ is the mean \pm SD of 3-6 separate experiments.

endothelial apoptosis. VEGF inhibits nuclear fragmentation that was abrogated by TSP (Fig. 1B, bottom row panels 2 and 3). TSP- induced leakage of mitochondrial cytochrome $\mathrm{c}$ in VEGF-treated cells was accompanied by nuclear fragmentation and apoptosis as seen on counter staining the nuclei with DAPI. Nuclear staining of cells treated with VEGF in the presence of TSP showed nuclear fragmentation, a characteristic feature of apoptosis (Fig. 1B). Therefore, TSP may prevent the survival-promoting effect of VEGF by stimulating cytochrome c release from mitochondria.

\section{TSP Abrogates VEGF-Induced Survival by Activating Caspase-3 and Cleavage of Poly-ADP-Ribose-Polymerase (PARP)}

In agreement with the above observations, VEGF prevented endothelial apoptosis and caspase-3 activation by $88 \%$ and $50 \%$, respectively (Figs. $\mathbf{2 A}$ and $\mathbf{B}$ ). Activation of caspase-3 leads to the cleavage of a $12 \mathrm{kD}$ fragment of caspase-3, which has been linked to the proteolytic cleavage of cellular substrates including PARP [33, 34]. Increased caspase-3 activity in serum-starved HDMEC was accompanied by the cleavage of a $12 \mathrm{kD}$ fragment of cytoplasmic pro-caspase-3 and cleavage of a $85 \mathrm{kD}$ fragment of nuclear PARP (Fig. 2C). VEGF inhibited the cleavage of caspase- 3 and PARP, whereas TSP blocked the inhibitory effect of VEGF on the inhibition of caspase-3 and PARP (Fig. 3C). The survival promoting effect of VEGF was significantly abrogated $(\sim 90 \%)$ in the presence of TSP $(\mathrm{p}<0.0001$, VEGF vs VEGF + TSP) (Fig. 2A) but the caspase-3 activity was increased by only $33 \%(\mathrm{p}<0.001)$ (Fig. 2B). This suggests that the apoptosis promoting effect of TSP on VEGF-induced EC survival is mediated only partly $(\sim 1 / 3)$ by the caspase-3-mediated mechanism. A time course of HDMEC undergoing apoptosis in serum-starved conditions showed that VEGF consistently promoted survival up to $72 \mathrm{~h}$ which was blocked by TSP (Fig. 2D). A cell permeable pan caspase inhibitor Z-VAD-FMK (carbobenzoxy-valyl-alanyl-aspartyl-[O-methyl]-fluoromethylketone) effectively inhibited the apoptotic effect of TSP on VEGF-stimulated HDMEC throughout the period of $24 \mathrm{~h}$ to $72 \mathrm{~h}(\mathrm{p}<0.0001$ VEGF+TSP $v s$. VEGF+TSP+Z-VAD-FMK at 24,48 and $72 \mathrm{~h}$ ). These data suggest that TSP promotes apoptosis in VEGF-stimulated HDMEC by a caspase-3 mediated activity. Antibodies to TGF- $\beta$ failed to influence 

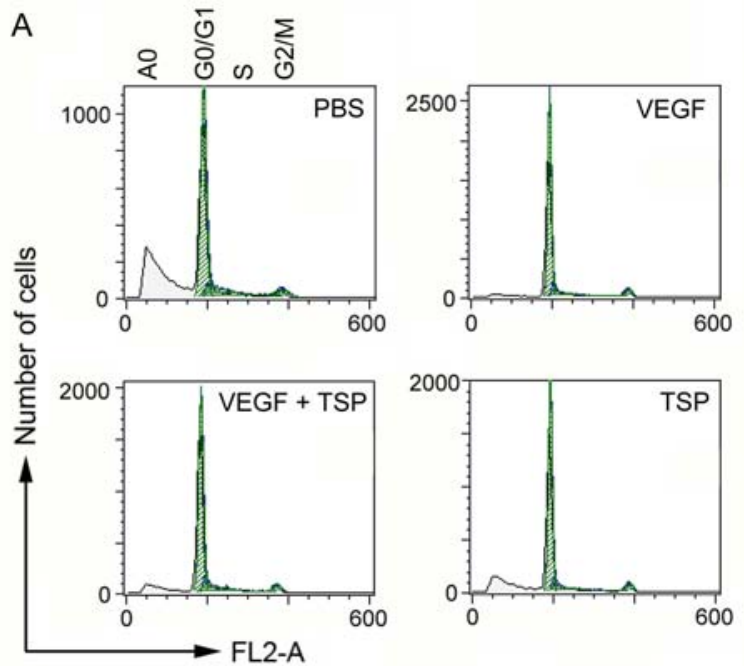

B

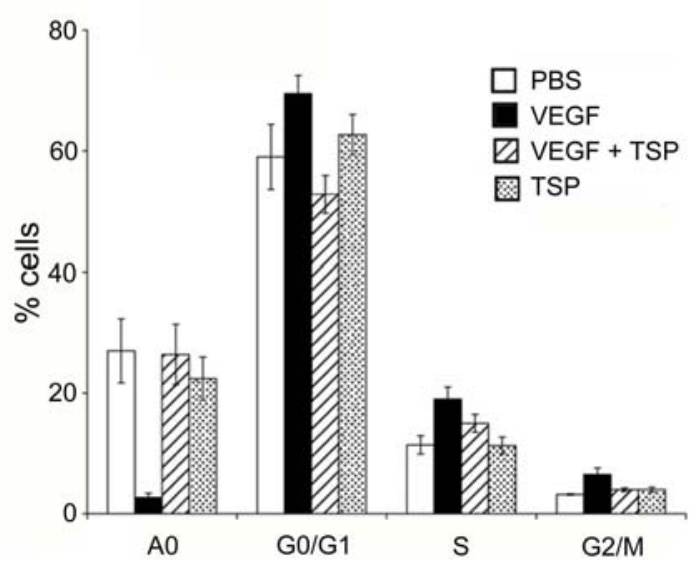

Fig. (3). TSP inhibits VEGF-induced cell cycle progression and promotes apoptosis. Serum and growth factor-starved HDMEC were incubated for $48 \mathrm{~h}$ with $100 \mathrm{ng} / \mathrm{ml}$ VEGF in the presence or absence of $10 \mathrm{ng} / \mathrm{ml} \mathrm{TSP}$ and cell cycle analysis performed by FACS. (A) Histograms showing the distribution of cells in different phases of cell cycle. Each histogram represents 5 reproducible experiments. (B) Percentage of cells in different phases of cell cycle. Each bar represents mean \pm SD of 5 separate experiments (Ao - PBS vs. VEGF <0.0001, VEGF $v s$. VEGF + TSP $<0.0001 ; \mathrm{G}_{0} / \mathrm{G}_{1}-\mathrm{VEGF} v s$ VEGF+TSP $<0.014 ; \mathrm{G}_{2} / \mathrm{M}-\mathrm{VEGF} v s$. VEGF+TSP $\left.<0.06\right)$.

the apoptotic effect of TSP (Fig. 2D). Thus, the apoptosisinducing effect of TSP is not due to contamination of TSP with TGF-B.

\section{Different Domains of TSP Participate in Inhibiting VEGF- Induced Survival}

We have shown earlier that different domains of TSP inhibit VEGF-induced HDMEC proliferation by using different mechanisms involving distinct regions of VEGF and several cell surface receptors [12]. We now demonstrate that these domains of TSP are also involved in inhibiting VEGF-induced HDMEC survival (Fig. 2A). Antibodies to different regions of TSP including $\mathrm{Ab} 9$ for the heparin binding domain (HBD), Ab 6.7 to the carboxy terminal domain or cell binding domain (CBD) and Abs 4.1, 6.1 and 4.6 to the type I, II and III repeats of TSP, respectively, completely abrogated the survival preventing effect of TSP on VEGF-induced survival $(\mathrm{p}<0.0001$ VEGF + TSP $v s$ VEGF + TSP + each Ab) (Fig. 2A). These findings suggest that all the domains of TSP are required for neutralizing the anti-apoptotic effect of VEGF. However, caspase activity was significantly inhibited only by antibodies $9,4.6$ and 6.7 that bind to the HBD, type III repeat region containing RGD and the CBD of TSP, respectively (Fig. 2B). Blockade of type I and type II repeats of TSP by Abs 4.1 and 6.1 also decreased the caspase-3 activity appreciably but it was not statistically significant. These data suggest that the HBD, RGD containing type III region and CBD are critical for activation of caspase-3, and that the type I and II regions may block VEGF-induced survival by other mechanisms.

\section{TSP Prevents VEGF-Induced Cell Cycle Progression}

Previous work suggests that VEGF promotes cell cycle progression as well as survival. Since cell cycle proteins (cyclins and their dependent kinases) and associated regulatory proteins (phosphatases, p21, p27) can orchestrate both cell survival and cell proliferation [19, 35], we examined the effect of TSP on cell cycle progression. We observed that VEGF prevented the apoptosis (A0 peak) of serum starved HDMEC by significantly promoting the progression of cell cycle in G0/G1, S and G2/M phase ( $\mathrm{p}<$ 0.05 serum free $v s$. VEGF for all three phases of the cell cycle) (Figs. 3A and B). TSP prevented the VEGF-induced cell cycle progression in $\mathrm{G} 0 / \mathrm{G} 1(\mathrm{p}<0.01)$ and decreased the number of cells in $\mathrm{S}$ and G2/M phase of cell cycle. The transition from $\mathrm{G} 1$ to $\mathrm{S}$ requires the temporal activation of cyclin E-CDK2, and cyclin A-CDK2. To further investigate the link between TSP-induced cell cycle arrest and cell cycle regulation we examined its influence on cell cycle proteins A and $\mathrm{E}$, their dependent kinases and the regulatory proteins $\mathrm{p} 21$ and $\mathrm{p} 27$.

\section{TSP Modulates Cell Cycle Checkpoints and Regulatory Proteins}

Cyclins $\mathrm{A}$ and $\mathrm{E}$ dependent kinase activity assayed in vitro using antibodies to cyclins $\mathrm{A}$ and $\mathrm{E}$ and histone $\mathrm{H} 1$ as substrate showed that VEGF increased the activity of both these kinases in serum-starved HDMEC (Fig. 4, lane 2). TSP impaired the VEGF-induced stimulation of cyclin A-CDK2 as well as cyclin E-CDK2. However, by itself TSP did not have any effect on these enzymes in serum-starved cells. Because CDK2 activity during $\mathrm{G} 1$ and $\mathrm{S}$ phase is induced in part through their association with cyclins A or E, we further studied the expression of these proteins. TSP downregulated the expression of both cyclin A as well as cyclin E in VEGFtreated cells (Fig. 4B). However, by itself TSP increased both cyclin $\mathrm{A}$ and $\mathrm{E}$ expression in serum-starved HDMEC. Cyclin A together with CDKs co-localizes with discrete sites of DNA replication in S phase nuclei, which are associated with the nuclear matrix and require an intact nuclear envelope for function [36]. The integrity of the nuclear membrane is disrupted in cells undergoing apoptosis. We found that in the presence of TSP, cyclin A diffused all over the cytoplasm as well as the nucleus in VEGF-stimulated cells (Fig. 4C). However, in VEGF-stimulated HDMEC cyclin A was densely localized in the nucleus. Therefore, 

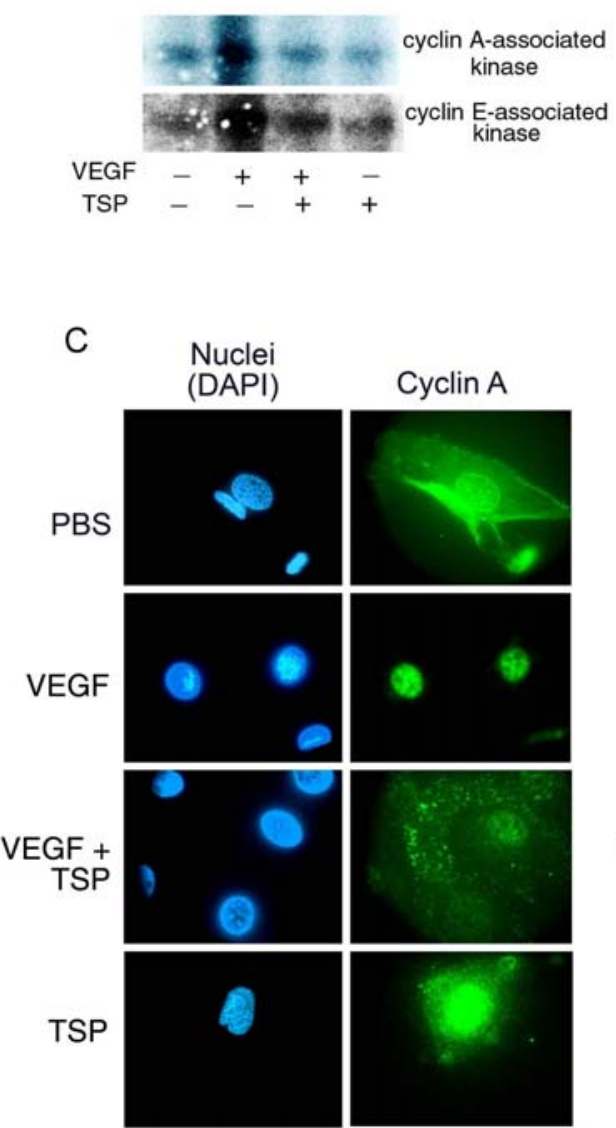

B

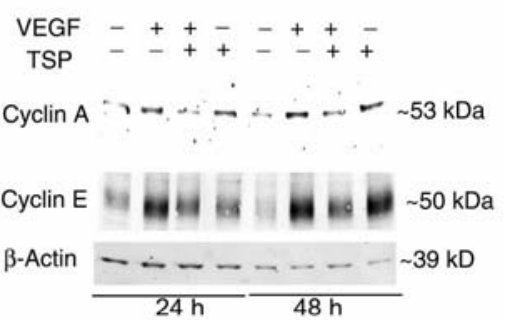

D
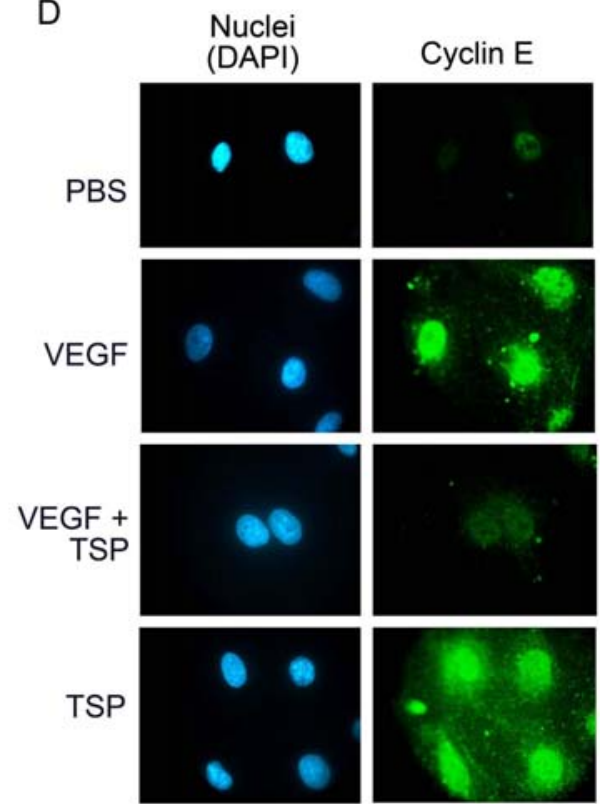

Fig. (4). TSP inhibits the activity of cell cycle regulatory proteins. Serum and growth factor-starved HDMEC were incubated with $100 \mathrm{ng} / \mathrm{ml}$ VEGF in the presence or absence of $10 \mathrm{ng} / \mathrm{ml}$ TSP. (A) After $48 \mathrm{~h}$ of incubation HDMEC were assayed for cyclin-A and -E associated in-gel kinase activity. (B) After 24 and 48h of incubation HDMEC were assayed for the expression of cyclin-A and -E by Western immunoblotting (C and D). Immunofluorescent staining for cyclin A and E (both in green) after 48h of incubation. Nuclei in blue show the nuclear and/or cytoplasmic co-localization of the cyclins. Each figure represents 4 reproducible experiments.

even though cyclin A is increased by TSP it leaks out of the nucleus and is ineffective in promoting cell cycle progression at the nuclear level. In serum-starved cells in the absence or presence of TSP, cyclin A was present throughout the cell cytoplasm and nucleus.

Because CDK2 activity can be negatively regulated through its association with the inhibitory proteins p21 and p27, we also analyzed the effect of TSP on these proteins in VEGF-stimulated HDMEC. VEGF inhibited both p21 and p27 expression in serum-starved HDMEC, TSP prevented its inhibitory effect on both p21 as well as p27 expression and also showed cleavage of a lower molecular weight fragment of both p21 and p27 (Fig. 5). TSP by itself did not show any appreciable effect on p21 or p27 and their cleaved fragments in serum-starved HDMEC (lane 4, Fig. 5). While the cleaved fragments of p21 appeared in appreciably high amounts, the cleaved fragment of p27 appeared in very low amounts. Thus, TSP inhibits VEGF-induced angiogenesis by simultaneously promoting apoptosis and cell cycle arrest.

\section{DISCUSSION}

TSP was the first anti-angiogenic factor to be identified [7]. The complexity of TSP structure due to its heterogeneous domains which bind to several known and possibly some unknown cell surface receptors have made it difficult to determine its mechanism(s) of action [15]. Binding of TSP to VEGF and displacement of VEGF from the cell surface shown by us [12] restricts the availability and therefore the activity of these heparin binding growth factors. At the cellular level, interaction of TSP 1 with cell

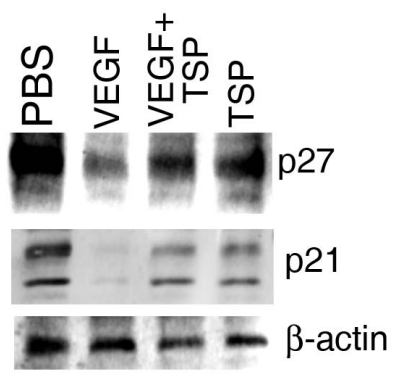

Fig. (5). Thrombospondin inhibits VEGF-induced downregulation of cyclin-dependent kinase inhibitors in HDMEC. Serum and growth factor-starved HDMEC were incubated with $100 \mathrm{ng} / \mathrm{ml}$ VEGF in the presence or absence of $10 \mathrm{ng} / \mathrm{ml}$ TSP and assayed for p21 and p27 by Western immunoblotting. Each figure represents 4 reproducible experiments. 
surface CD36 leading to the activation of Fyn-caspase-3p38MAPK cascade is one of the leading anti-angiogenic mechanism of TSP action [9]. TSP inhibits both survival as well as angiogenesis. Caspase activation and the involvement of several other proposed mechanisms $(\mathrm{Bcl} 2$, JNK, p38MAPK, FAS, etc) suggest that TSP inhibits endothelial survival $[9,10]$. However, TSP does not affect endothelial survival in normal/quiescent endothelium. It only inhibits endothelial proliferation in vessels undergoing angiogenesis, where the concentration of growth promoting cytokines such as VEGF is abnormally high. TSP inhibits the growth promoting effect of these growth factors on endothelium by mechanisms that inhibit both proliferation as well as survival.

Cytochrome c which normally resides exclusively in mitochondria, is released into the cytosol during apoptosis [37]. Release of cytochrome $c$ from the mitochondria triggers caspase activation through Apaf-1 [38]. We observed that TSP neutralized the survival promoting effect of VEGF on HDMEC in serum-starved conditions. This was accompanied by the activation of caspase- 3 activity, which was significantly higher in TSP-treated cells with VEGF as compared to VEGF alone treated cells $(p=0.0004)$. Seeking additional evidence that TSP acts via a mitochondria dependent mechanism to induce apoptosis, we analyzed cytochrome c leakage from mitochondria into cytosolic fractions of HDMEC. Serum-starved HDMEC treated with VEGF alone showed the presence of cytochrome c only in the mitochondrial fraction and did not show any detectable cytochrome $\mathrm{c}$ in cytoplasmic fractions of the cells. However, in the presence of TSP, we detected cytochrome $\mathrm{c}$ in the cytoplasmic as well as the mitochondrial fraction. IF staining of monolayers with anti-cytochrome c FITC confirmed the localization of cytochrome $\mathrm{c}$ in the mitochondria in VEGFtreated cells. Cells treated with both VEGF and TSP showed diffuse staining all over the cell, consistent with leakage of cytochrome c from mitochondria and activation of caspase- 3 .

Caspase-mediated activation of CDK inhibitors p21 and p27 can be instrumental in the execution of apoptosis following caspase activation [39]. Because CDK2 activity is required for the progression of the cell cycle from $\mathrm{G} 1$ to $\mathrm{S}$ phase, we reasoned that the inhibition of CDK2 which is complexed to cyclin A and E, by active p21 and p27 will lead to cell cycle arrest in G1 phase of cell cycle.

Critical events occur during the G1 phase of the cell cycle that determine whether a cell will continue to proliferate or will withdraw from the cell cycle and undergo apoptosis [40]. It is well known that cell cycle proteins (cyclins and their dependent kinases) and associated regulatory proteins (phosphatases, p16, p21, p27) can orchestrate both cell survival and cell proliferation. We observed that TSP did influence cell cycle regulation of VEGF-stimulated HDMEC. TSP caused a $20 \%$ increase in apoptotic cells and cell cycle arrest of VEGF-stimulated HDMEC in the G0/G1 phase of the cell cycle $(\mathrm{p}=0.014)$. Its influence on cell cycle proteins was dual. Cyclin A and E associated with the regulation of different cell cycle checkpoints were regulated by TSP in VEGF-stimulated cells. Moreover, in the presence of TSP cyclin A and E diffused all over the cell cytoplasm as well as the nucleus. However, in VEGF-stimulated HDMEC cyclins A and E were densely localized in the nucleus. Since cyclins regulate the cell cycle by complexing with their respective kinases, we looked at cyclin A and E dependent kinases. Cyclin Aand $\mathrm{E}$ - dependent kinase activity was significantly reduced in the presence of TSP in VEGF-stimulated HDMEC.

Cyclins and CDKs are, in turn, regulated by phosphatases. Activated caspases have been suggested to lead to the truncation of CDK2 inhibitors, p21 and p27 [33, 38]. We observed that TSP stimulated the upregulation and cleavage of p21 and p27 proteins in VEGF-stimulated HDMEC. More than $75 \%-80 \%$ of CDK2 and cyclin A are associated with both p21 and p27 and the cleaved fragments of p21 and p27 orchestrate CDK2 inhibition [39, 41-43]. Therefore, downregulation of cyclin A and cyclin E in TSPtreated VEGF-stimulated HDMEC appears to be due to the regulation of cyclins by $\mathrm{p} 21$ and p27. CDK-I p27 inhibits cell proliferation and apoptosis by binding to and inhibiting Cyclin A-CDK and Cyclin E-CDK complexes and regulates G0 to $S$ phase transition [44]. Therefore, increased p27 levels leads to increased number of cells in G0/G1 and A0 phases of the cell cycle and a decrease in cyclin A and E associated kinase activity in HDMEC treated with TSP in the presence of VEGF as compared to VEGF alone.

Complementary to our observations on the regulation of cell cycle by TSP, earlier studies from our laboratory showed that in the presence of TSP with VEGF cell numbers were reduced after 48 hours of culture as compared to cultures containing VEGF alone [12]. A decrease in cell number, promotion of apoptosis and cell cycle arrest induced by TSP in VEGF-containing cultures suggest that TSP might be modulating cell cycle regulatory checkpoints and proteins. Moreover, different domains of TSP abrogated VEGFinduced HDMEC proliferation [15]. We now observed that the same domains of TSP were also involved in inhibiting VEGF-induced HDMEC survival. Each of these domains interacts with specific cell surface receptors (CD36, $\alpha v \beta 3$, HSPG, CBD). Although it appears that any one region of TSP is adequate to inhibit the survival promoting activity of VEGF, the whole TSP protein appears to be required to completely abrogate the growth- and survival-promoting activity of VEGF. We speculate that inhibition of binding of any one of the domains of TSP may impair its interaction with VEGF and/or the endothelial cell, making it inactive towards inhibiting VEGF-induced survival. Earlier studies have shown that type- 1 repeat peptides of TSP have a proapoptotic effect on endothelial cells [45]. However, in a recent study CD36 binding peptides from TSP and a CD36neutralizing antibody did not abrogate TSP-1-induced cell cycle arrest [14].

In conclusion, our data show that TSP promotes apoptosis and inhibits cell cycle progression that is stimulated by VEGF in HDMEC. The survival inhibiting activities of TSP are due to the stimulation of mitochondrial cytochrome $\mathrm{c}$ release and increased caspase- 3 activation followed by cleavage of nuclear PARP. TSP-induced caspase activation coincides with the upregulation of $\mathrm{CDK}$ inhibitors p21 and p27, inhibition of cyclin A and E dependent kinases, inhibition of cell cycle progression and promotion of apoptosis in VEGF-stimulated HDMEC. Therefore, TSP inhibits VEGF-induced cell cycle 
progression and survival by stimulating cell cycle arrest and apoptosis.

\section{ACKNOWLEDGEMENTS}

We thank Rong Luo and Carol Taubert for technical and editorial assistance, respectively. This work was funded by PO1 HL55552 to R.P.H and HL06882 to K.G.

\section{REFERENCES}

\section{REFERENCES}

[1] Folkman, J. Angiogenesis in cancer, vascular, rheumatoid and other disease. Nat. Med., 1995, l(1), 27-31.

[2] Gupta, K.; Zhang, J. Angiogenesis: A curse or cure? Postgrad. Med. J., 2005, 81, 236-242.

[3] Hanahan, D.; Folkman, J. Patterns and emerging mechanisms of the angiogenic switch during tumorigenesis. Cell, 1996, 86(3), 353364.

[4] Armstrong, L. C.; Bornstein, P. Thrombospondins 1 and 2 function as inhibitors of angiogenesis. Matrix Biol., 2003, 22(1), 63-71.

[5] Kalluri, R. Basement membranes: structure, assembly and role in tumour angiogenesis. Nat. Rev. Cancer, 2003, 3(6), 422-433.

[6] Lawler, J. J. Thrombospondin-1 as an endogenous inhibitor of angiogenesis and tumor growth. Cell Mol. Med., 2002, 6(1), 1-12.

[7] Folkman, J. Endogenous angiogenesis inhibitors. APMIS, 2004, 112(7-8), 496-507.

[8] Reiher, F. K.; Volpert, O. V.; Jimenez, B.; Crawford, S. E.; Dinney, C. P.; Henkin, J.; Haviv, F.; Bouck, N. P.; Campbell, S. C. Inhibition of tumor growth by systemic treatment with thrombospondin-1 peptide mimetics. Int. J. Cancer, 2002, 98(5), 682-689.

[9] Jimenez, B.; Volpert, O. V.; Crawford, S. E.; Febbraio, M.; Silverstein, R. L.; Bouck, N. Signals leading to apoptosisdependent inhibition of neovascularization by thrombospondin-1. Nat. Med., 2000, 6(1), 41-48.

[10] Volpert, O. V.; Zaichuk, T.; Zhou, W.; Reiher, F.; Ferguson, T. A.; Stuart, P. M.; Amin, M.; Bouck, N. P. Inducer-stimulated Fas targets activated endothelium for destruction by anti-angiogenic thrombospondin-1 and pigment epithelium-derived factor. Nat. Med., 2002, 8(4), 349-357.

[11] Rege, T. A.; Stewart, J., Jr.; Dranka, B.; Benveniste, E. N.; Silverstein, R. L.; Gladson, C. L. J. Thrombospondin-1-induced apoptosis of brain microvascular endothelial cells can be mediated by TNF-R1. J. Cell Physiol., 2009, 218(1), 94-103.

[12] Gupta, K.; Gupta, P.; Wild, R.; Ramakrishnan, S.; Hebbel, R. P. Binding and displacement of vascular endothelial growth factor (VEGF) by thrombospondin: effect on human microvascular endothelial cell proliferation and angiogenesis. Angiogenesis, 1999, 3(2), 147-158.

[13] Nor, J. E.; Mitra, R. S.; Sutorik, M. M.; Mooney, D. J.; Castle, V. P.; Polverini, P. J. Thrombospondin-1 induces endothelial cell apoptosis and inhibits angiogenesis by activating the caspase death pathway. J. Vasc. Res., 2000, 37(3), 209-218.

[14] Yamauchi, M.; Imajoh-Ohmi, S.; Shibuya, M. Novel antiangiogenic pathway of thrombospondin-1 mediated by suppression of the cell cycle. Cancer Sci., 2007, 98(9), 1491-1497.

[15] Gupta, K.; Gupta, P.; Solovey, A.; Hebbel, R. P. Mechanism of interaction of thrombospondin with human endothelium and inhibition of sickle erythrocyte adhesion to human endothelial cells by heparin. Biochim. Biophys. Acta, 1999, 1453(1), 63-73.

[16] Thompson, C. B. Apoptosis in the pathogenesis and treatment of disease. Science, 1995, 267(5203), 1456-1462.

[17] Danial, N. N.; Korsmeyer, S. J. Cell death: critical control points. Cell, 2004, 116(2), 205-219.

[18] Fesik, S. W. Promoting apoptosis as a strategy for cancer drug discovery. Nat. Rev. Cancer, 2005, 5(11), 876-885.

[19] Sherr, C. J. Cancer cell cycles. Science, 1996, 274(5293), 16721677.

[20] Bocci, G.; Francia, G.; Man, S.; Lawler, J.; Kerbel, R. S. Thrombospondin 1, a mediator of the antiangiogenic effects of lowdose metronomic chemotherapy. Proc. Natl. Acad. Sci. USA, 2003, 100(22), 12917-12922.

[21] Niu, Q.; Perruzzi, C.; Voskas, D.; Lawler, J.; Dumont, D. J.; Benjamin, L. E. Inhibition of Tie-2 signaling induces endothelial cell apoptosis, decreases Akt signaling, and induces endothelial cell expression of the endogenous anti-angiogenic molecule, thrombospondin-1. Cancer Biol. Ther., 2004, 3(4), 402-405.

[22] Sherr, C. J.; Roberts, J. M. Inhibitors of mammalian G1 cyclindependent kinases. Genes Dev., 1995, 9(10), 1149-1163.

[23] Sang, L.; Coller, H. A.; Roberts, J. M. Control of the reversibility of cellular quiescence by the transcriptional repressor HES1. Science, 2008, 321(5892), 1095-1100.

[24] Bocci, G.; Nicolaou, K. C.; Kerbel, R. S. Protracted low-dose effects on human endothelial cell proliferation and survival in vitro reveal a selective antiangiogenic window for various chemotherapeutic drugs. Cancer Res., 2002, 62(23), 6938-6943.

[25] Senger, D. R.; Galli, S. J.; Dvorak, A. M.; Perruzzi, C. A.; Harvey, V. S.; Dvorak, H. F. Tumor cells secrete a vascular permeability factor that promotes accumulation of ascites fluid. Science, 1983, 219(4587), 983-985.

[26] Risau, W.; Mechanisms of angiogenesis. Nature, 1997, 386(6626), 671-674.

[27] Ferrara, N.; Henzel, W. J. Pituitary follicular cells secrete a novel heparin-binding growth factor specific for vascular endothelial cells. Biochem. Biophys. Res. Commun., 1989, 161(2), 851-858.

[28] Plate, K. H.; Breier, G.; Weich, H. A.; Risau, W. Vascular endothelial growth factor is a potential tumour angiogenesis factor in human gliomas in vivo. Nature, 1992, 359(6398), 845-848.

[29] Gupta, K.; Ramakrishnan, S.; Browne, P. V.; Solovey, A.; Hebbel, R. P. A novel technique for culture of human dermal microvascular endothelial cells under either serum-free or serum-supplemented conditions: isolation by panning and stimulation with vascular endothelial growth factor. Exp. Cell Res., 1997, 230(2), 244-251.

[30] Fan, T.; Lu, H.; Hu, H.; Shi, L.; McClarty, G. A.; Nance, D. M.; Greenberg, A. H.; Zhong, G. Inhibition of apoptosis in chlamydiainfected cells: blockade of mitochondrial cytochrome c release and caspase activation. J. Exp. Med., 1998, 187(4), 487-496.

[31] Gupta, K.; Kshirsagar, S.; Li, W.; Gui, L.; Ramakrishnan, S. Gupta, P.; Law, P. Y.; Hebbel, R. P. VEGF prevents apoptosis of human microvascular endothelial cells via opposing effects on MAPK/ERK and SAPK/JNK signaling. Exp. Cell Res., 1999, 247(2), 495-504.

[32] Gupta, K.; Kshirsagar, S.; Chang, L.; Schwartz, R.; Law, P. Y.; Yee, D.; Hebbel, R. P. Morphine stimulates angiogenesis by activating proangiogenic and survival-promoting signaling and promotes breast tumor growth. Cancer Res., 2002, 62(15), 44914498.

[33] Tewari, M.; Quan, L. T.; O'Rourke, K.; Desnoyers, S.; Zeng, Z.; Beidler, D. R.; Poirier, G. G.; Salvesen, G. S.; Dixit, V. M. Yama/CPP32 beta, a mammalian homolog of CED-3, is a CrmAinhibitable protease that cleaves the death substrate poly(ADPribose) polymerase. Cell, 1995, 81(5), 801-809.

[34] Nicholson, D. W.; Ali, A.; Thornberry, N. A.; Vaillancourt, J. P.; Ding, C. K.; Gallant, M.; Gareau, Y.; Griffin, P. R.; Labelle, M.; Lazebnik, Y. A. Identification and inhibition of the ICE/CED-3 protease necessary for mammalian apoptosis. Nature, 1995, 376(6535), 37-43.

[35] Elledge, S. J. Cell cycle checkpoints: preventing an identity crisis. Science, 1996, 274(5293), 1664-1672.

[36] Cardoso, M. C.; Leonhardt, H.; Nadal-Ginard, B. Reversal of terminal differentiation and control of DNA replication: cyclin A and Cdk2 specifically localize at subnuclear sites of DNA replication. Cell, 1993, 74(6), 979-992.

[37] Liu, X.; Kim, C. N.; Yang, J.; Jemmerson, R.; Wang, X. Induction of apoptotic program in cell-free extracts: requirement for dATP and cytochrome c. Cell, 1996, 86(1), 147-157.

[38] Li, P.; Nijhawan, D.; Budihardjo, I.; Srinivasula, S. M.; Ahmad, M.; Alnemri, E. S.; Wang, X. Cytochrome c and dATP-dependent formation of Apaf-1/caspase-9 complex initiates an apoptotic protease cascade. Cell, 1997, 91(4), 479-489.

[39] Levkau, B.; Koyama, H.; Raines, E. W.; Clurman, B. E.; Herren, B.; Orth, K.; Roberts, J. M.; Ross, R. Cleavage of p21Cip1/Waf1 and p27Kip1 mediates apoptosis in endothelial cells through activation of Cdk2: role of a caspase cascade. Mol. Cell, 1998, 1(4), 553-563.

[40] Pardee, A. B. G1 events and regulation of cell proliferation. Science, 1989, 246(4930), 603-608.

[41] Chen, J.; Jackson, P. K.; Kirschner, M. W.; Dutta, A. Separate domains of p21 involved in the inhibition of Cdk kinase and PCNA. Nature, 1995, 374(6520), 386-388. 
[42] Luo, Y.; Hurwitz, J.; Massague, J. Cell-cycle inhibition by independent CDK and PCNA binding domains in p21Cip1. Nature, 1995, 375(6527), 159-161.

[43] Fotedar, R.; Fitzgerald, P.; Rousselle, T.; Cannella, D.; Doree, M.; Messier, H.; Fotedar, A. p21 contains independent binding sites for cyclin and cdk2: both sites are required to inhibit cdk2 kinase activity. Oncogene, 1996, 12(10), 2155-2164.
[44] Chu, I. M.; Hengst, L.; Slingerland, J. M. The Cdk inhibitor p27 in human cancer: prognostic potential and relevance to anticancer therapy. Nat. Rev. Cancer, 2008, 8(4), 253-267.

[45] Guo, N.; Krutzsch, H. C.; Inman, J. K.; Roberts, D. D. Thrombospondin 1 and type I repeat peptides of thrombospondin 1 specifically induce apoptosis of endothelial cells. Cancer Res., 1997, 57(9), 1735-1742.

Received: November 10, 2008

Revised: November 11, 2008

Accepted: November 17, 2008

(c) Gupta et al.; Licensee Bentham Open.

This is an open access article licensed under the terms of the Creative Commons Attribution Non-Commercial License (http://creativecommons.org/licenses/by-nc/3.0/) which permits unrestricted, non-commercial use, distribution and reproduction in any medium, provided the work is properly cited. 